\title{
Perfusion of Isolated Carotid Sinus With Hydrogen Sulfide Attenuated the Renal Sympathetic Nerve Activity in Anesthetized Male Rats
}

\author{
Qi GUO ${ }^{1}$, Yuming WU ${ }^{1}$, Hongmei XUE ${ }^{1}$, Lin XIAO ${ }^{1}$, Sheng JIN ${ }^{1}$, Ru WANG ${ }^{1}$ \\ ${ }^{1}$ Department of Physiology, Institute of Basic Medicine, Hebei Medical University, Shijiazhuang, \\ China
}

Received April 7, 2015

Accepted December 4, 2015

On-line March 15, 2016

\section{Summary}

The purpose of the present study was to define the indirect central effect of hydrogen sulfide $\left(\mathrm{H}_{2} \mathrm{~S}\right)$ on baroreflex control of sympathetic outflow. Perfusing the isolated carotid sinus with sodium hydrosulfide (NaHS), a $\mathrm{H}_{2} \mathrm{~S}$ donor, the effect of $\mathrm{H}_{2} \mathrm{~S}$ was measured by recording changes of renal sympathetic nerve activity (RSNA) in anesthetized male rats. Perfusion of isolated carotid sinus with $\mathrm{NaHS}(25,50,100 \mu \mathrm{mol} / \mathrm{l})$ dose and timedependently inhibited sympathetic outflow. Preconditioning of glibenclamide $(20 \mu \mathrm{mol} / \mathrm{l})$, a ATP-sensitive $\mathrm{K}^{+}$channels ( $\mathrm{K}_{\text {ATP }}$ ) blocker, the above effect of NaHS was removed. With 1, 4-dihydro-2, 6-dimethyl-5-nitro-4-(2-[trifluoromethyl] phenyl) pyridine-3-carboxylic acid methyl ester (Bay K8644, $500 \mathrm{nmol} / \mathrm{l}$ ) pretreatment, which is an agonist of L-calcium channels, the effect of NaHS was eliminated. Perfusion of cystathionine $y$-lyase (CSE) inhibitor, DL-propargylglycine (PPG, $200 \mu \mathrm{mol} / \mathrm{l}$ ), increased sympathetic outflow. The results show that exogenous $\mathrm{H}_{2} \mathrm{~S}$ in the carotid sinus inhibits sympathetic outflow. The effect of $\mathrm{H}_{2} \mathrm{~S}$ is attributed to opening $\mathrm{K}_{\text {ATP }}$ channels and closing the L-calcium channels.

\section{Key words}

Hydrogen sulfide • Renal sympathetic nerve activity • Isolated carotid sinus • Baroreflex • ATP-sensitive $\mathrm{K}^{+}$channels

\section{Corresponding author}

Y. Wu, Department of Physiology, Institute of Basic Medicine, Hebei Medical University, 361 Zhongshan East Road, Shijiazhuang 050017, China. E-mail: wuyum@yahoo.com

\section{Introduction}

Hydrogen sulfide $\left(\mathrm{H}_{2} \mathrm{~S}\right)$ is considered as a toxic gas for the past decades. However, $\mathrm{H}_{2} \mathrm{~S}$ has recently been known as a new gaseous messenger molecule in many physiological and pathophysiologic processes, similar to the other gastransmitters, nitric oxide (NO) and carbon monoxide (CO) (Eto and Kimura 2002, Fiorucci et al. 2006, Kimura 2002). Endogenous $\mathrm{H}_{2} \mathrm{~S}$ is produced from cysteine by pyridoxal-5'-phosphate (PLP)-dependent enzymes, including cystathionine $\beta$-synthase (CBS) and cystathionine $\gamma$-lyase (CSE) (Stipanuk 2004, Stipanuk and Beck 1982). 3-mercaptopyruvate sulfurtransferase (3-MST), a PLP-independent enzyme, is additional possible way to produce $\mathrm{H}_{2} \mathrm{~S}$ (Shibuya et al. 2009, Stipanuk and Beck 1982). The distribution of these enzymes is tissue specific, and CSE is the mainly enzyme which produced hydrogen sulfide in the cardiovascular system (Zhao et al. 2001).

A growing number of reports suggested $\mathrm{H}_{2} \mathrm{~S}$ is involved in many fundamental physiopathology processes including nociception, neuroprotection, cardiovascular functions, inflammation and apoptosis (Li and Moore 2008, Wang 2003, Zhao et al. 2001). $\mathrm{H}_{2} \mathrm{~S}$ can activate ATP-sensitive $\mathrm{K}^{+}$channels $\left(\mathrm{K}_{\text {ATP }}\right)$ in smooth muscle to induce vasodilation in the blood vessel (Zhao et al. 2001). Kubo et al. (2007) also have shown sodium hydrosulfide (NaHS), a $\mathrm{H}_{2} \mathrm{~S}$ donor, causes relaxation of aorta in rat and mouse while the relaxation effect of NaHS is partially mediated by $\mathrm{K}_{\text {ATP }}$ channels (Kubo et al. 2007). Moreover, $\mathrm{H}_{2} \mathrm{~S}$ can regulate $\mathrm{Ca}^{2+}$ homeostasis of human vascular endothelial, suggesting that $\mathrm{H}_{2} \mathrm{~S}$ may 
decrease blood pressure via the above effect (Bauer et al. 2010). There is a result suggests that $\mathrm{H}_{2} \mathrm{~S}$ play a negative chronotropic action on pacemaker cells in sinoatrial nodes of rabbits. These effects are likely due to opening $\mathrm{K}_{\mathrm{ATP}}$ channels and increasing in potassium efflux (Xu et al. 2008). $\mathrm{H}_{2} \mathrm{~S}$ also activates transient receptor potential ankyrin 1 (TRPA1) channels in sensory nerves and then causes vasodilatation in isolated small pressurized mesenteric arteries from rats (White et al. 2013).

Arterial baroreflex has been considered to be the major negative-feedback system that steadies systemic arterial pressure (AP) against pressure disturbance. The baroreflex consists of two subsystems: neural and peripheral arc (Ikeda et al. 1996). The neural arc characterizes the input-output relation of baroreceptor pressure and sympathetic nerve activity (SNA), while the peripheral arc represents the relationship between SNA and AP (Ikeda et al. 1996, Kawada et al. 2005). In our laboratory, we have demonstrated that $\mathrm{H}_{2} \mathrm{~S}$ may dosedependently facilitate the carotid sinus baroreflex and baroreceptor activity (Xiao et al. 2006, 2007). We also have demonstrated $\mathrm{H}_{2} \mathrm{~S}$ inhibits sympathetic vasomotor tone by opening a $\mathrm{K}_{\mathrm{ATP}}$ channels in the rostral ventrolateral medulla (RVLM) (Guo et al. 2011). Nevertheless, the indirect central effects of $\mathrm{H}_{2} \mathrm{~S}$ on baroreflex control of sympathetic outflow have not been reported.

In the present study, we want to reveal the indirect central effect of perfusion of isolated carotid sinus with NaHS on sympathetic outflow by recording renal sympathetic nerve activity (RSNA) and to define the possible mechanisms.

\section{Materials and Methods}

\section{Animal}

Male Sprague-Dawley rats, weighting 290-310 g Grade II, were obtained from the Experimental Animal Center of Hebei Province, China. Rats were housed in $12 \mathrm{~h} \mathrm{light/dark}$ cycle. Food and water were freely available. The animals were adapted to the environment for about a week before the experiment. All protocols and procedures used in this study were reviewed and approved by the Institutional Animal Ethics Committee of Hebei Medical University and in accordance with the Guide for the Care and Use of Laboratory Animals (1985, NIH).

\section{Recording of RSNA}

General operation was performed as described before (Guo et al. 2011). Anesthetized was induced by urethane $(1.0 \mathrm{~g} / \mathrm{kg}$ i.p. $)$. The trachea was cannulated for breathing. Body temperature was maintained at $37-38^{\circ} \mathrm{C}$ by using a thermostatic bed. A left flank incision was made and then the left kidney was visualized by retroperitoneal. One branch of the renal sympathetic nerves was hooked up with a bipolar platinum electrode for recording efferent potential. The distal end of the nerve was clamped to eliminate the afferent activity and then immersed in warm $\left(37^{\circ} \mathrm{C}\right)$ liquid paraffin oil to keep moist. The recording electrode was connected with a set of biological polygraph (RM6240BD, Chengdu Technology) to record RSNA simultaneously. Integrate of RSNA was automatically by the computer and the integrated time was $0.16 \mathrm{~s}$. At the end of the experiment, the head end of the nerve was clamped to get the noise level of RSNA.

\section{Perfusion of left isolated carotid sinus}

Isolated carotid sinus was perfused with a method as we previously reported (Xiao et al. 2006). Turn the trachea and esophagus to head in order to fully expose the areas of carotid sinus. The left carotid sinus nerve was carefully retention. The rest buffer nerves and other nerves around the carotid sinus were all cut. The vascular of the left carotid sinus was isolated from systemic circulation by ligating the external and internal carotid arteries and its branches originating from the carotid sinus regions. In order to exclude the effect of chemoreceptors, occipital artery was ligated at its initial part that preventing activation of chemoreceptor secondary to decrease carotid sinus pressure. Plastic catheters were placed into the left carotid artery and the external carotid artery respectively served as inlet and outlet tubes. The carotid sinus was then perfused with warm $\left(37^{\circ} \mathrm{C}\right)$ oxygenated modified Krebs-Henseleit (K-H) solution (mmol/l: $\mathrm{NaCl} 118.0, \mathrm{KCl} 4.7, \mathrm{CaCl}_{2} 2.5$, $\mathrm{MgSO}_{4}$ 1.6, $\mathrm{KH}_{2} \mathrm{PO}_{4} 1.2, \quad \mathrm{NaHCO}_{3} 25$, glucose 5.6, pH 7.35-7.45) bubbled with $95 \% \mathrm{O}_{2}$ and $5 \% \mathrm{CO}_{2}$.

The inlet tube connected with a pressure transducer (YPJ01, Chengdu Technology) was recorded intrasinus pressure (ISP). ISP was controlled by a peristaltic pump and a program designed by our laboratory (Xiao et al. 2006). After finished the above operation, ISP was kept at $100 \mathrm{~mm} \mathrm{Hg}$ for $20 \mathrm{~min}$. When checked the baroreflex, ISP was lowered to $0 \mathrm{~mm} \mathrm{Hg}$ rapidly and then increased to $250 \mathrm{~mm} \mathrm{Hg}$ in the form of 
pulsatile ramp. It took $0.5 \mathrm{~min}$ for ISP to be increased from 0 to $250 \mathrm{~mm} \mathrm{Hg}$. ISP and RSNA were simultaneously recorded on a polygraph (RM6240BD, Chengdu Technology). Every $5 \mathrm{~min}$, repeat the above process to check the stability of the baroreflex. Reproducibility drops of RSNA in response to the increase in ISP were documented.

\section{Protocols}

The left carotid sinus was perfused with $\mathrm{K}-\mathrm{H}$ solution. As the ISP change from 0 to $250 \mathrm{~mm} \mathrm{Hg}$, we observe the difference between the maximum and the minor integral value of RSNA which was recorded as a $100 \%$.

Each experimental group was performed on six rats. ISP was fixed at $100 \mathrm{~mm} \mathrm{Hg}$ for $20 \mathrm{~min}$ with $\mathrm{K}-\mathrm{H}$ solution. Baseline ISP-RSNA was measured when the isolated carotid sinus was perfused with K-H solution. After we got the baseline ISP-RSNA, then NaHS (25, 50 or $100 \mu \mathrm{mol} / \mathrm{l}$ ) were added into K-H solution. The isolated carotid sinus was perfused with the solution for $50 \mathrm{~min}$, and then ISP-RSNA was measured again. The concentrations of NaHS were perfused in random order. One dose was performed on one rat.

We tested the effect of glibenclamide, a $\mathrm{K}_{\text {ATP }}$ channels-antagonist $(20 \mu \mathrm{mol} / \mathrm{l})$, on NaHS-induce effect of ISP-RSNA. We first perfused the isolated carotid sinus with NaHS $(50 \mu \mathrm{mol} / \mathrm{l})$ to observe the effect on ISPRSNA. After the ISP-RSNA returned to baseline, glibenclamide $(20 \mu \mathrm{mol} / \mathrm{l})$ was perfused for $15 \mathrm{~min}$ before another dose of NaHS $(50 \mu \mathrm{mol} / \mathrm{l})$. To determine whether $\mathrm{Ca}^{2+}$ was involved in the effect of NaHS on ISP-RSNA, Bay K8644 (500 nmol/1), an agonist of $\mathrm{Ca}^{2+}$ channels, was perfused into the isolated carotid sinus to open the $\mathrm{Ca}^{2+}$ channels. To further determine the effect of endogenous $\mathrm{H}_{2} \mathrm{~S}$ on ISP-RSNA, we compared ISP-RSNA recorded during the administration of cystathionine $\gamma$-lyase (CSE) inhibitor, DL-propargylglycine (PPG) $(200 \mu \mathrm{mol} / \mathrm{l})$.

\section{Western blot analysis}

We used Western blot to determine the expression of CSE in carotid sinus. After experiment, the bilateral carotid sinus were rapidly removed and put in liquid nitrogen and then stored at $-80{ }^{\circ} \mathrm{C}$ for further analysis. The tissue were homogenized in $100 \mu l$ lysing buffer and then centrifuged at $15,000 \mathrm{~g}$ for $20 \mathrm{~min}$ at $4{ }^{\circ} \mathrm{C}$. We collected supernatant for protein assay. Bradford assay was used to determine the concentration of protein in tissue. The protein was denatured at $99{ }^{\circ} \mathrm{C}$ for $10 \mathrm{~min}$. Then protein of $50 \mu \mathrm{g}$ was loaded in each lane of SDS-PAGE gels. After electrophoresis, the protein was separated then transferred onto polyvinylidene fluoride (PVDF) membranes. The transferred PVDF membranes were blocked with $5 \%$ skim milk in TBST ( $1.37 \mathrm{mmol} / 1 \mathrm{NaCl}, 200 \mathrm{mmol} / 1 \mathrm{~T}$ Tris, $0.05 \%$ Tween-20, $\mathrm{pH}$ 7.5) for $1 \mathrm{~h}$. The PVDF membranes were incubated with primary antibody (anti-mouse CSE polyclonal antibody, 1:500, Proteintech Biotechnology) overnight followed by appropriate secondary horseradish peroxidase-conjugated antibody (1:2000, Proteintech Biotechnology). Western blotting reagents (Millipore Corporation, Billerica, MA01821, USA) were used to detect the signal. The chemiluminescent signals obtained were recorded. We have used Photoshop to modulate the lightness of the photographies (Fig. 6).

\section{Drugs}

NaHS (purity $99 \%$, Sigma, St Louis, MO, USA) was dissolved in saline. Bay K8644 (1, 4-dihydro-2, 6-dimethyl-5-nitro-4-(2-[trifluoromethyl]phenyl) pyridine -3-carboxylic acid methyl ester, $\mathrm{C}_{16} \mathrm{H}_{15} \mathrm{~F}_{3} \mathrm{~N}_{2} \mathrm{O}_{4}$ ) was purchased from Sigma and dissolved in $99 \%$ ethyl alcohol. Glibenclamide (5-chloro-N-[4-(cyclo hexylureidosulfonyl) phenethyl]-2-methoxybenzamide, $\mathrm{C}_{23} \mathrm{H}_{28} \mathrm{ClN}_{3} \mathrm{O}_{5} \mathrm{~S}$ ) was obtained from Alfa Aesar (Ward Hill, MA, USA) and dissolved in dimethyl sulphoxide (DMSO, $\left(\mathrm{CH}_{3}\right)_{2} \mathrm{SO}$ ). The final concentration of dimethyl sulphoxide or ethyl alcohol in the K-H solution was lower than $0.05 \%$. PPG (DL-propargylglycine, $\mathrm{C}_{5} \mathrm{H}_{7} \mathrm{NO}_{2}$ ) was obtained from Sigma and dissolved in $\mathrm{K}-\mathrm{H}$ solution.

\section{Statistics}

All data were reported as means \pm SD. ANOVA was applied to compare differences between groups and Student-Newman-Keuls test and Dunnett's t-test were used to further analyze. The lever of significance was set at $\mathrm{P}<0.05$.

\section{Results}

\section{Effect of NaHS on ISP-RSNA}

Perfused the left carotid sinus with NaHS $(25,50,100 \mu \mathrm{mol} / \mathrm{l})$ reflexly decreased RSNA in a concentration-dependent manner (Fig. 1). After NaHS $(25,50,100 \mu \mathrm{mol} / \mathrm{l})$ were perfused, RSNA was decreased to $84.95 \pm 3.58 \%(\mathrm{P}<0.01), 63.89 \pm 2.53 \%(\mathrm{P}<0.01)$ and 
$48.70 \pm 4.16 \% \quad(\mathrm{P}<0.01)$ respectively, compared with control. The response of ISP-RSNA to NaHS appeared obvious changes approximately $30 \mathrm{~min}$ after perfusing the isolated carotid sinus with NaHS, reached maximum response at about $40 \mathrm{~min}$. Recoveries were of no effect on ISP-RSNA at $30-50 \mathrm{~min}$ after washout. When we perfused $100 \mu \mathrm{mol} / 1 \mathrm{NaHS}$, the response appeared earlier but it was needed long time to recover completely about $50 \mathrm{~min}$.

NaHS $50 \mu \mathrm{mol} / 1$ produced reproducible effect on ISP-RSNA. It took about $40 \mathrm{~min}$ to recover. Therefore, NaHS $50 \mu \mathrm{mol} / 1$ was selected to test mechanistic evaluation and also present time-dependent changes in Figure 2.

A

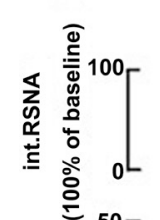

KH
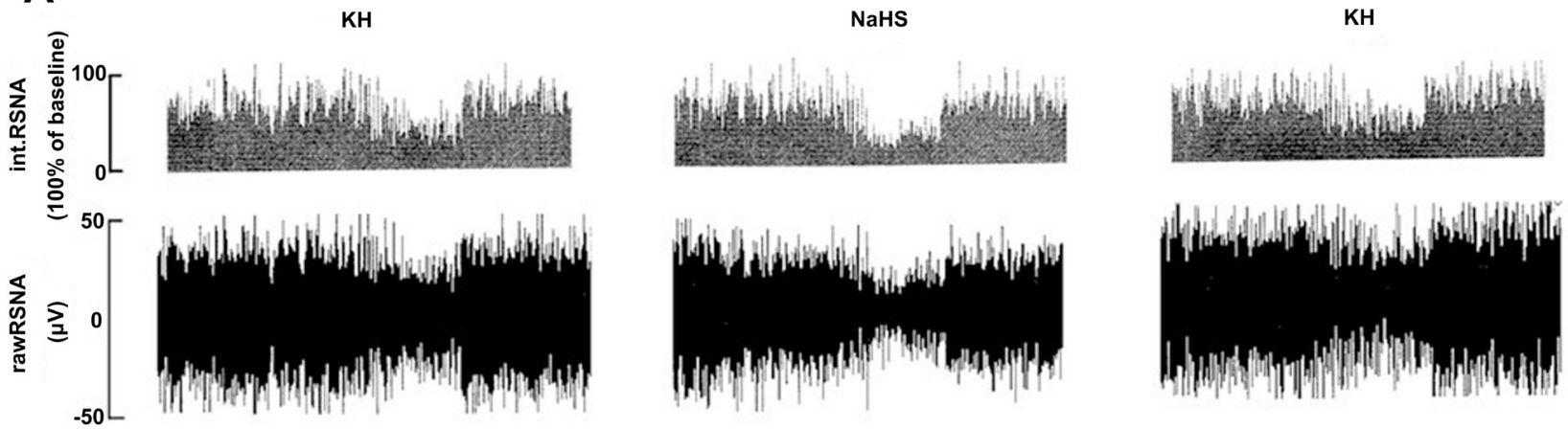

을
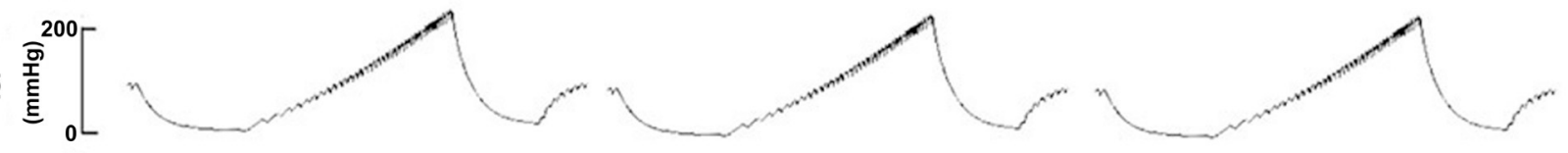

B

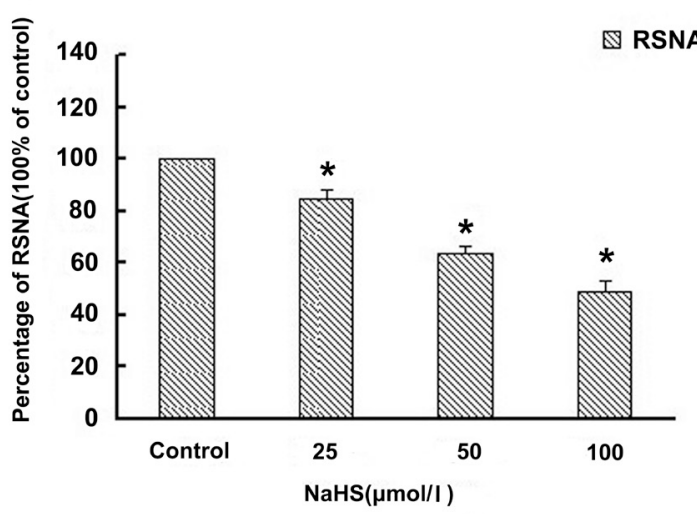

Fig. 1. Effect of isolated carotid sinus perfused with NaHS. (A) Original tracing recordings showing the effect of $\mathrm{NaHS}(50 \mu \mathrm{mol} / \mathrm{l})$ perfused into the isolated carotid sinus on RSNA. "int.RSNA" means integral of RSNA, the unit is changes of baseline (\%); "rawRSNA" means original RSNA, the unit is $\mu \mathrm{V}$. (B) Summary data showing the effects of isolated carotid sinus perfused with NaHS (25, 50, $100 \mu \mathrm{mol} / \mathrm{l})$ on RSNA in anesthetized male rats $(n=6)$. Data are means \pm SD. $* P<0.05$ compared with control value.

\section{Effect of glibenclamide on NaHS-induced response}

To testify the role of $\mathrm{K}_{\mathrm{ATP}}$ in the action of NaHS $(50 \mu \mathrm{mol} / 1)$ in this study, glibenclamide $(20 \mu \mathrm{mol} / \mathrm{l})$ was perfused the isolated carotid sinus followed by initial NaHS $(50 \mu \mathrm{mol} / \mathrm{l})$. ISP-RSNA was compared between NaHS group and group given NaHS plus glibenclamide. The effect of NaHS on ISP-RSNA was blocked by glibenclamide (Fig. 3).

The vehicle of glibenclamide $(0.01 \%$ dimethyl sulphoxide in K-H solution) showed no effect on the above parameters.

Effect of Bay K8644 on the response of ISP-RSNA to NaHS

We used Bay K8644 to prove whether $\mathrm{Ca}^{2+}$ is involved in the action of NaHS to ISP-RSNA. In six rats, after the initial effect of NaHS $(100 \pm 0 \%$ to $65.56 \pm 6.87 \%$ ) perfusion into the isolated carotid sinus on ISP-RSNA, Bay K8644 (500 nmol/1) was perfused into the isolated carotid sinus. ISP-RSNA did not respond to 
Bay K8644. Following the subsequent NaHS (50 $\mu \mathrm{mol} / \mathrm{l})$ perfusion, ISP-RSNA decreased from $100 \pm 0 \%$ to $95.15 \pm 8.2 \%(\mathrm{P}<0.01)$. There is significance difference compared with the initial effect of NaHS perfusion into the isolated carotid sinus $(\mathrm{P}<0.05)$ (Fig. 4). The vehicle of Bay K8644 (0.05 \% ethyl alcohol in K-H solution) was perfused again, and showed no statistical effect on the above parameters.

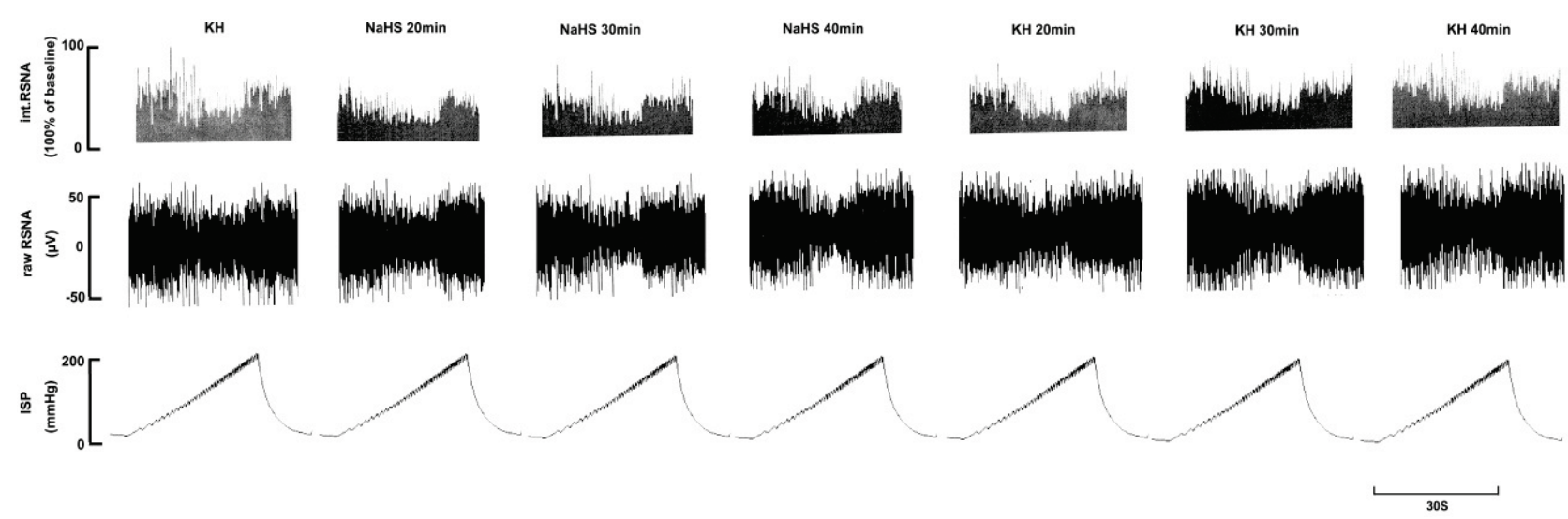

Fig. 2. A time dependent changes of the ISP-RSNAS before and after isolated carotid sinus perfused with NaHS. Original tracing recordings showing the effect of NaHS (50 $\mu \mathrm{mol} / \mathrm{l})$ perfused into the isolated carotid sinus on RSNA. "int.RSNA" means integral of RSNA, the unit is changes of baseline (\%); "rawRSNA" means original RSNA, the unit is $\mu \mathrm{V}$.

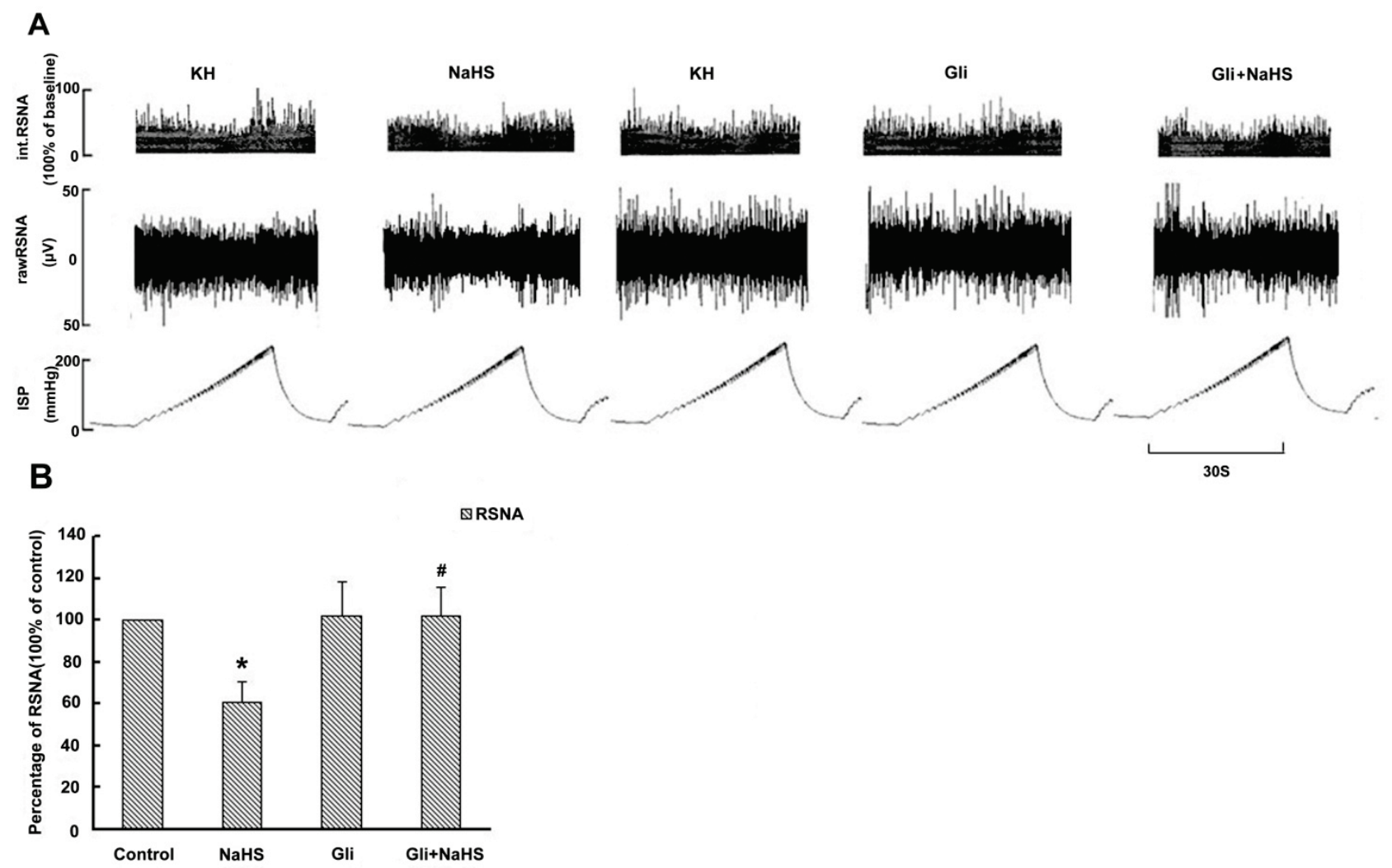

Fig. 3. Effect of glibenclamide (Gli, $20 \mu \mathrm{mol} / \mathrm{l}$ ) on the response of RSNA to $50 \mu \mathrm{mol} / \mathrm{l}$ NaHS. (A) Original tracing recordings showing the effect of NaHS $(50 \mu \mathrm{mol} / \mathrm{l})$, glibenclamide, and NaHS plus glibenclamide perfused into the isolated carotid sinus on RSNA. "int.RSNA" means integral of RSNA, the unit is changes of baseline (\%); "rawRSNA" means original RSNA, the unit is $\mu \mathrm{V}$. (B) Summary data showing the effect of NaHS, glibenclamide, and NaHS plus glibenclamide perfusion into the isolated carotid sinus on RSNA ( $n=6)$. Data are means \pm SD. * $\mathrm{P}<0.05$ compared with control value. \# $\mathrm{P}<0.05$, compared with $\mathrm{NaHS}(50 \mu \mathrm{mol} / \mathrm{l})$. 


\section{Effect of PPG on ISP-RSNA}

To determine the effect of endogenous $\mathrm{H}_{2} \mathrm{~S}$ on ISP-RSNA, we perfused PPG, to inhibit synthesis of $\mathrm{H}_{2} \mathrm{~S}$. After perfusion of PPG $(200 \mu \mathrm{mol} / \mathrm{l})$, RSNA increased significantly from $100 \pm 0 \%$ to $118.43 \pm 8.04 \%(\mathrm{P}<0.01)$. PPG inhibits the CSE in male rats and suppresses the response of RSNA to the increased ISP (Fig. 5).

\section{Expression of CSE in isolated carotid sinus}

Western blot was performed to detect the protein expression of CSE in carotid sinus of control, PPG and Bay K8644. As the result shown in Figure 6, grey bands represented the CSE positive signals.

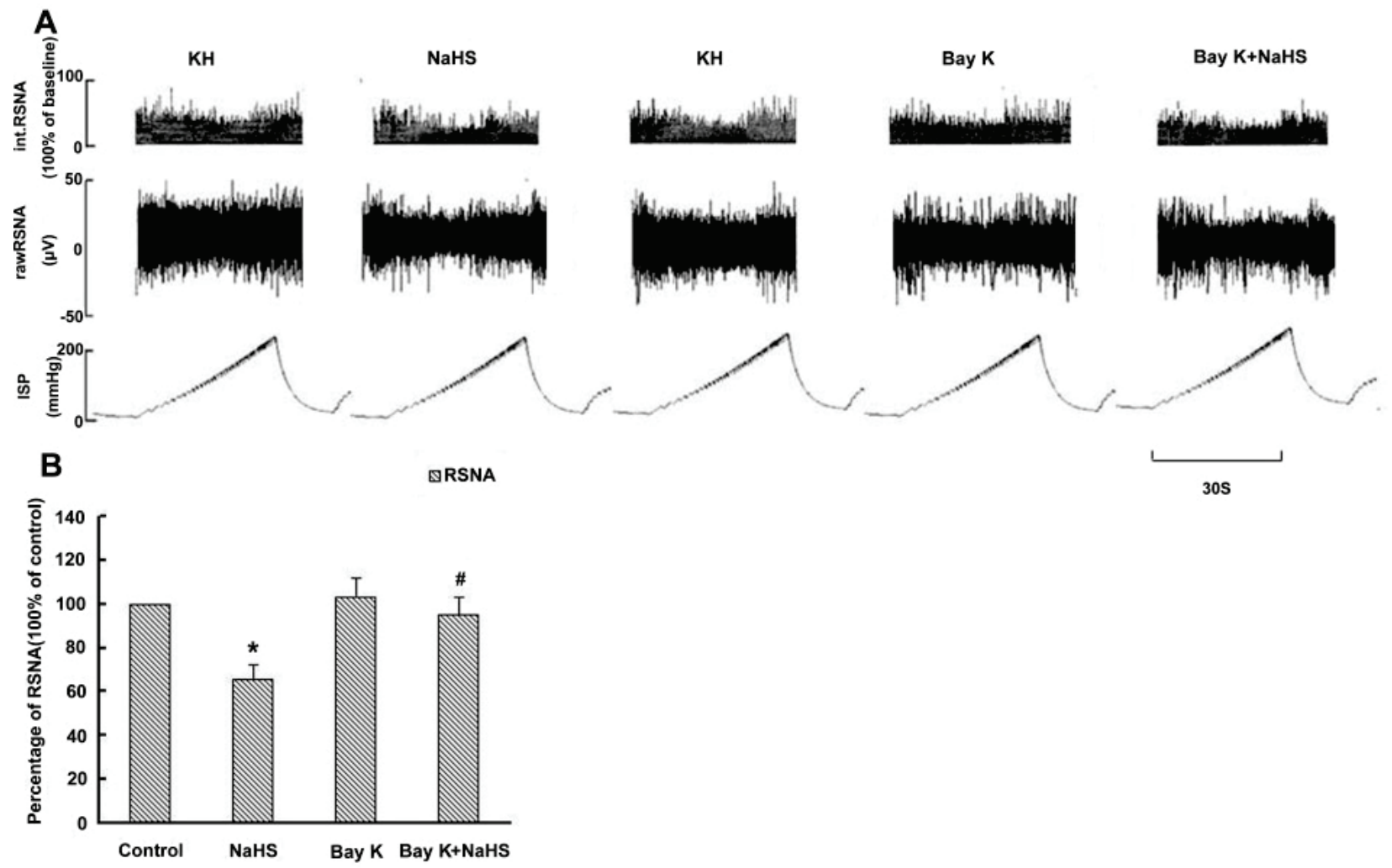

Fig. 4. Effect of Bay $\mathrm{K} 8644(500 \mathrm{nmol} / \mathrm{l})$ on the response of RSNA to $50 \mu \mathrm{mol} / \mathrm{l} \mathrm{NaHS}$. (A) Original tracing recordings showing the effect of NaHS $(50 \mu \mathrm{mol} / \mathrm{l})$, Bay K8644, and NaHS plus Bay K8644 perfused into the isolated carotid sinus on RSNA. "int.RSNA" means integral of RSNA, the unit is changes of baseline (\%); "rawRSNA" means original RSNA, the unit is $\mu$ V. (B) Summary data showing the effect of NaHS, Bay K8644, and NaHS plus Bay K8644 perfusion into the isolated carotid sinus on RSNA $(n=6)$. Data are means \pm SD. $* P<0.05$ compared with control value. \# P<0.05, compared with NaHS (50 $\mu \mathrm{mol} / \mathrm{l})$.

\section{Discussion}

The present study was designed to demonstrate the indirect central effect of $\mathrm{H}_{2} \mathrm{~S}$ on baroreflex control of the sympathetic outflow. The finding showed that perfusion isolated carotid sinus with NaHS dose and time-dependently inhibited sympathetic outflow that is in the form of increasing response of RSNA to ISP. When we perfused largest dose, the inhibit effect appeared earlier and needed long time to wash out. Compared with our previous studies, we further revealed the effect of hydrogen sulfide on baroreflex control of sympathetic outflow. As we all known, activation of the sympathetic system is the main cause of hypertension. The results imply $\mathrm{H}_{2} \mathrm{~S}$ modulate SNA by baroreflex and sensitization of the baroreflex control of RSNA in order to stability the blood pressure.

Resistance to the treatment of hypertension may be due in part to inadequate inhibition of the sympathetic nervous system (Egan et al. 2010). Renal sympathetic nerve activity is an important direct indicator for the evaluation of sympathetic central activity. Increased RSNA can contribute to the genesis of hypertension both directly by increasing reabsorption of tubular water and sodium and indirectly by increasing the secretion of renin, which activates the renin-angiotensin system resulting in increased vascular resistance and reduced GFR (DiBona 2000). The preclinical researches target 
carotid sinuses (Baroreflex Activation Therapy) invasive therapy for the treatment of drug-resistant hypertension. Stimulation of carotid baroreceptors by suppressing sympathetic tone can induce sustained decrease in arterial pressure and heart rate (Briasoulis and Bakris 2012, 2014). Thereafter, $\mathrm{H}_{2} \mathrm{~S}$ may have possible therapeutic potential in some cardiovascular disease especially in patients with resistant hypertension.

A

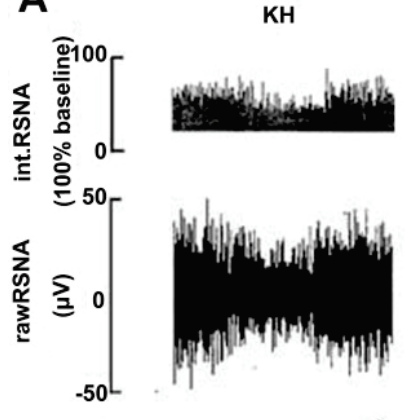

PPG
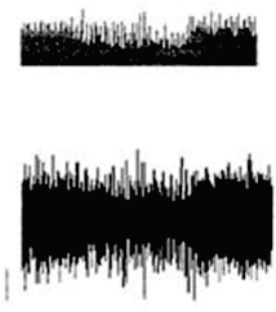

KH
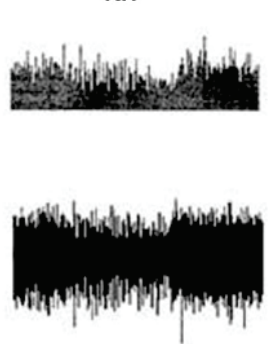

을

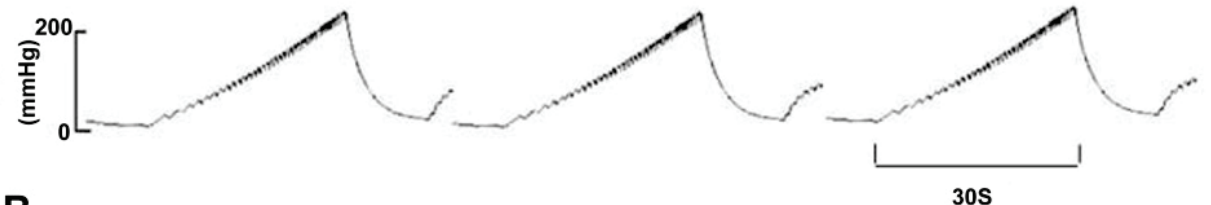

B

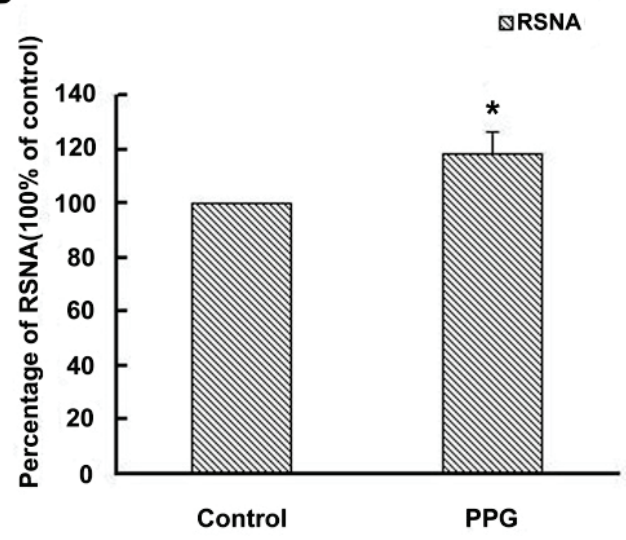

Fig. 5. Effect of PPG $(200 \mu \mathrm{mol} / \mathrm{l})$ on the response of RSNA. (A) Original tracing recordings showing the effect of PPG ( $200 \mu \mathrm{mol} / \mathrm{l})$ perfusion into the isolated carotid sinus on RSNA. "int.RSNA" means integral of RSNA, the unit is changes of baseline (\%); "rawRSNA" means original RSNA, the unit is $\mu \mathrm{V}$. (B) Summary data showing the effect of PPG $(200 \mu \mathrm{mol} / \mathrm{l})$ perfusion into the isolated carotid sinus on RSNA. Data are means $\pm \mathrm{SD}$. $* \mathrm{P}<0.05$ compared with control value.

NaHS is commonly used as an $\mathrm{H}_{2} \mathrm{~S}$ donor since it dissociates to $\mathrm{Na}^{+}$and $\mathrm{HS}^{-}$, the latter then partially binds $\mathrm{H}^{+}$to form undissociated $\mathrm{H}_{2} \mathrm{~S}$ (Lowicka and Beltowski 2007). $\mathrm{H}_{2} \mathrm{~S}$ readily dissolves in water, and dissociates to $\mathrm{H}^{+}$, $\mathrm{HS}^{-}$, and $\mathrm{S}^{2-}$. Under physiological conditions, approximately $20 \%$ exist as $\mathrm{H}_{2} \mathrm{~S}$ and the remaining $80 \%$ as $\mathrm{HS}^{-}$, with only trace amounts of $\mathrm{S}^{2-}$. The term "hydrogen sulfide" has been used to refer to $\mathrm{H}_{2} \mathrm{~S}, \mathrm{HS}^{-}$, and $\mathrm{S}^{2-}$ (Abe and Kimura 1996). Once generated, $\mathrm{H}_{2} \mathrm{~S}$ can be oxidized to generate reductant-labile sulfane sulfur pools, which include hydrodisulfides/persulfides. When we perfused carotid sinus with NaHS, it is possible to restore oxygen to produce superoxide anion. However, superoxide may contribute to the pathogenesis of many diseases and damage the function of baroreflex (Zhang et al. 2014). It is opposite to our results. Maybe superoxide play minimum role in our results. Polysulfide is a bound sulfur species derived from endogenous $\mathrm{H}_{2} \mathrm{~S}$ (Koike et al. 2013). Polysulfide contains sulfane sulfur and also exerts much more cytoprotective effects. Oxidized sulfide, such as persulfide thiosulfate $\left(\mathrm{S}_{2} \mathrm{O}_{3}{ }^{2-}\right)$ and sulfate $\left(\mathrm{SO}_{4}{ }^{2-}\right)$ which a downstream product of $\mathrm{H}_{2} \mathrm{~S}$, also plays cytoprotective effects (Sakaguchi et al. 2014, Schreurs and Cipolla 2013). Meanwhile, $\mathrm{H}_{2} \mathrm{~S}$ can also be released from bound sulfane sulfur pools (Kimura 2014). There is a dynamic balance between them (Bailey et al. 2014, Vitvitsky et al. 2012). In our present experiment, it is difficult to make a distinction effect between them. Even if the other products exert cytoprotective effects and that is still to be attributed to $\mathrm{H}_{2} \mathrm{~S}$. 
A

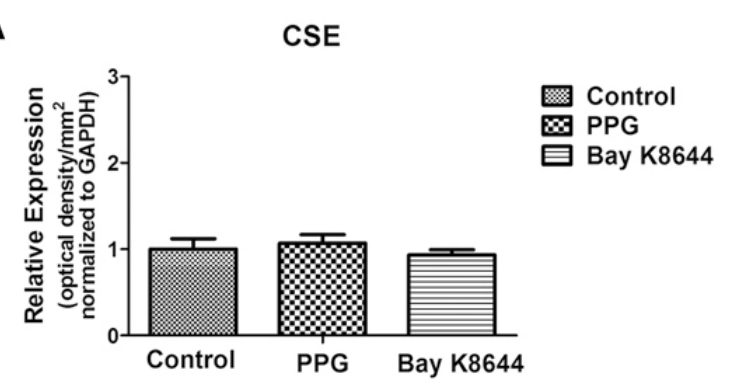

B

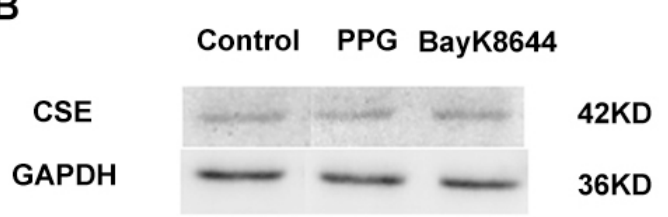

Fig. 6. Expression of CSE in isolated carotid sinus. (A) Protein expression of CSE in carotid sinus from control, PPG and Bay K8644 group $(n=6)$. GAPDH was used to normalize. Data are means \pm SD. (B) Representative original illustrating of Western blot in control, PPG and Bay K8644 group.

Evidences have been present to show that endogenous $\mathrm{H}_{2} \mathrm{~S}$ in mammalian tissues play a significant role in the cardiovascular system (Elrod et al. 2007, Geng et al. 2004, Zhao et al. 2001). There are some studies have reported that $\mathrm{H}_{2} \mathrm{~S}$ can relax isolated aorta and the mesenteric artery in rat, and that the vasodilatation induced by $\mathrm{H}_{2} \mathrm{~S}$ is attributable to activation of $\mathrm{K}_{\mathrm{ATP}}$ channels (Cheng et al. 2004, Zhao and Wang 2002, Zhao et al. 2001). High concentration of $\mathrm{K}^{+}$ions attenuated vasorelaxation induced by $\mathrm{H}_{2} \mathrm{~S}$ in aortic ring, and $\mathrm{H}_{2} \mathrm{~S}$-mediated vasodilatation was effectively blocked by glibenclamide or 5-hydroxydecanoate (5-HD), $\mathrm{K}_{\mathrm{ATP}}$ channels antagonists (Ali et al. 2006, Johansen et al. 2006, Zhu et al. 2007). A similar study also has been reported by Webb et al. (2008) and by Tang et al. (2005) glibenclamide can block the relaxant response to $\mathrm{H}_{2} \mathrm{~S}$ in phenylephrine precontracted human internal mammary artery. However, glibenclamide was also reported to inhibit chloride intracellular channels (Kominkova et al. 2013). If glibenclamide inhibit chloride channels, it will cause hyperpolarization and then relaxation of sinus wall which will increase the effect of $\mathrm{H}_{2} \mathrm{~S}$. But in our study, the effect of $\mathrm{H}_{2} \mathrm{~S}$ was blocked by glibenclamide. As a result, glibenclamide may be possible mainly play a role as a $\mathrm{K}_{\mathrm{ATP}}$ channels blocker in our experiment. It is conceivable that the effect of $\mathrm{H}_{2} \mathrm{~S}$ is mediated by opening a $\mathrm{K}_{\text {ATP }}$ channels in smooth muscle cell and then dilation of sinus wall. The relaxation of sinus wall will enhance stretch of baroreceptors. On the other side, mechanosensitive channels on baroreceptors will be activated and result in reducing RSNA. However, we cannot rule out the directly effect of $\mathrm{H}_{2} \mathrm{~S}$ on mechanosensitive channels on baroreceptor.

Bay K8644, a specific agonist of L-type $\mathrm{Ca}^{2+}$ channels, is used to further detect whether $\mathrm{H}_{2} \mathrm{~S}$ acts on L-type $\mathrm{Ca}^{2+}$ channels. The result of the experiment that the inhibitory effect of $\mathrm{H}_{2} \mathrm{~S}$ on sympathetic outflow was significantly blocked by Bay K8644, powerfully imply that $\mathrm{H}_{2} \mathrm{~S}$-mediate-inhibitory effect might be attributed to the close of L-type $\mathrm{Ca}^{2+}$ channels. The present data is similar to that of our previous study, which shows that $\mathrm{H}_{2} \mathrm{~S}$ can act on L-type $\mathrm{Ca}^{2+}$ channels and significantly inhibit $\mathrm{Ca}^{2+}$ influx (Xiao et al. 2006, Xu et al. 2008). As we all known that $\mathrm{K}_{\text {ATP }}$ channels can inhibit the $\mathrm{Ca}^{2+}$ influx through L-type $\mathrm{Ca}^{2+}$ channels (Cifelli et al. 2008, Jovanovic and Jovanovic 2001). Therefore, it may be proposed that $\mathrm{H}_{2} \mathrm{~S}$ might first open the $\mathrm{K}_{\text {ATP }}$ channels and cause $\mathrm{K}^{+}$outflow then result in hyperpolarisation, which subsequently inhibit $\mathrm{Ca}^{2+}$ influx via $\mathrm{L}$-type voltage-gated calcium channels and prevent excessive $\mathrm{Ca}^{2+}$ in smooth muscle cell. However, Bay K8644 can open calcium channels and the protein of CSE can be affected by calcium in the cell. We tested the expression of CSE after perfusion Bay K8644, there was no significance difference compared with control. This result implied Bay K8644 has not affected the product of endogenous $\mathrm{H}_{2} \mathrm{~S}$ and only inhibited the effect of $\mathrm{H}_{2} \mathrm{~S}$.

Previously data have shown expression of CSE in vascular tissues and that the production of $\mathrm{H}_{2} \mathrm{~S}$ was inhibited by PPG (Yan et al. 2004, Zhao et al. 2001). PPG, a potent nonreversible inhibitor of CSE, was used to inhibit the production of $\mathrm{H}_{2} \mathrm{~S}$ (Thompson et al. 1982). In our current experiments, perfusing the left carotid sinus with PPG induced an increase in RSNA compared with control application of $\mathrm{K}-\mathrm{H}$ solution. In addition, our present study has shown CSE positive signal is distributed in carotid sinus even though there is no significant difference between PPG and control group. The effect of PPG is due to the down production of endogenous $\mathrm{H}_{2} \mathrm{~S}$ by inhibiting CSE in carotid sinus wall. Moreover, the inhibition did not affect the quantity of CSE protein and only inhibit the function of CSE in our experiment. Meanwhile, the expression of CSE in carotid sinus is an extra evidence that endogenous $\mathrm{H}_{2} \mathrm{~S}$ produced by CSE tonically suppresses the sympathetic vasomotor by activation of the carotid sinus baroreflex (CSB). And that distinguish from the exogenous $\mathrm{H}_{2} \mathrm{~S}$ which depended on dose and time.

In summary, the present study has demonstrated 
that perfusion of isolated carotid sinus with NaHS inhibited sympathetic outflow in the form of increased the response of ISP-RSNA. Endogenous $\mathrm{H}_{2} \mathrm{~S}$ maintain the blood pressure in a basal level through modulating the carotid sinus baroreflex. Sympathetic outflow play an important role in some cardiovascular disease. Therefore, our data imply that $\mathrm{H}_{2} \mathrm{~S}$ may be a novel intervention that can be used in clinical.

\section{Conflict of Interest}

There is no conflict of interest.

\section{Acknowledgements}

This work is supported by Program for Natural science foundation of China (31171098), New Century Excellent Talents in University by the Education Ministry of China (NO. NCET-07-0252) and by higher innovation team leading talent cultivation plan of Hebei (LJRC017).

\section{References}

ABE K, KIMURA H: The possible role of hydrogen sulfide as an endogenous neuromodulator. J Neurosci 16: 10661071, 1996.

ALI MY, PING CY, MOK YY, LING L, WHITEMAN M, BHATIA M, MOORE PK: Regulation of vascular nitric oxide in vitro and in vivo; a new role for endogenous hydrogen sulphide? Br J Pharmacol 149: 625-634, 2006.

BAILEY TS, ZAKHAROV LN, PLUTH MD: Understanding hydrogen sulfide storage: probing conditions for sulfide release from hydrodisulfides. J Am Chem Soc 136: 10573-10576, 2014.

BRIASOULIS A, BAKRIS GL: Timing and efficacy of alternative methods of sympathetic blockade. Curr Hypertens Rep 14: 455-461, 2012.

BRIASOULIS A, BAKRIS G: The future of interventional management of hypertension: threats and opportunities. Curr Vasc Pharmacol 12: 69-76, 2014.

CHENG Y, NDISANG JF, TANG G, CAO K, WANG R: Hydrogen sulfide-induced relaxation of resistance mesenteric artery beds of rats. Am J Physiol Heart Circ Physiol 287: H2316-H2323, 2004.

CIFELLI C, BOUDREAULT L, GONG B, BERCIER JP, RENAUD JM: Contractile dysfunctions in ATP-dependent $\mathrm{K}^{+}$channel-deficient mouse muscle during fatigue involve excessive depolarization and $\mathrm{Ca}^{2+}$ influx through L-type $\mathrm{Ca}^{2+}$ channels. Exp Physiol 93: 1126-1138, 2008.

DIBONA GF: Neural control of the kidney: functionally specific renal sympathetic nerve fibers. Am J Physiol Regul Integr Comp Physiol 279: R1517-R1524, 2000.

EGAN BM, ZHAO Y, AXON RN: US trends in prevalence, awareness, treatment, and control of hypertension, 1988-2008. JAMA 303: 2043-2050, 2010.

ELROD JW, CALVERT JW, MORRISON J, DOELLER JE, KRAUS DW, TAO L, JIAO X, SCALIA R, KISS L, SZABO C, KIMURA H, CHOW CW, LEFER DJ: Hydrogen sulfide attenuates myocardial ischemiareperfusion injury by preservation of mitochondrial function. Proc Natl Acad Sci U S A 104: 15560-15565, 2007.

ETO K, KIMURA H: The production of hydrogen sulfide is regulated by testosterone and S-adenosyl-L-methionine in mouse brain. J Neurochem 83: 80-86, 2002.

FIORUCCI S, DISTRUTTI E, CIRINO G, WALLACE JL: The emerging roles of hydrogen sulfide in the gastrointestinal tract and liver. Gastroenterology 131: 259-271, 2006.

GENG B, YANG J, QI Y, ZHAO J, PANG Y, DU J, TANG C: $\mathrm{H}_{2} \mathrm{~S}$ generated by heart in rat and its effects on cardiac function. Biochem Biophys Res Commun 313: 362-368, 2004.

IKEDA Y, KAWADA T, SUGIMACHI M, KAWAGUCHI O, SHISHIDO T, SATO T, MIYANO H, MATSUURA W, ALEXANDER J JR, SUNAGAWA K: Neural arc of baroreflex optimizes dynamic pressure regulation in achieving both stability and quickness. Am J Physiol 271: H882-H890, 1996.

JOHANSEN D, YTREHUS K, BAXTER GF: Exogenous hydrogen sulfide $\left(\mathrm{H}_{2} \mathrm{~S}\right)$ protects against regional myocardial ischemia-reperfusion injury - Evidence for a role of K ATP channels. Basic Res Cardiol 101: 53-60, 2006.

JOVANOVIC S, JOVANOVIC A: Pinacidil prevents membrane depolarisation and intracellular $\mathrm{Ca}^{2+}$ loading in single cardiomyocytes exposed to severe metabolic stress. Int J Mol Med 7: 639-643, 2001. 
KAWADA T, YAMAMOTO K, KAMIYA A, ARIUMI H, MICHIKAMI D, SHISHIDO T, SUNAGAWA K, SUGIMACHI M: Dynamic characteristics of carotid sinus pressure-nerve activity transduction in rabbits. Jpn $J$ Physiol 55: 157-163, 2005.

KIMURA H: Hydrogen sulfide as a neuromodulator. Mol Neurobiol 26: 13-19, 2002.

KIMURA H: Hydrogen sulfide and polysulfides as biological mediators. Molecules 19: 16146-16157, 2014.

KOIKE S, OGASAWARA Y, SHIBUYA N, KIMURA H, ISHII K: Polysulfide exerts a protective effect against cytotoxicity caused by t-buthylhydroperoxide through Nrf2 signaling in neuroblastoma cells. FEBS Lett $\mathbf{5 8 7}$ : 3548-3555, 2013.

KOMINKOVA V, ONDRIAS K, TOMASKOVA Z: Inhibitory effect of glybenclamide on mitochondrial chloride channels from rat heart. Biochem Biophys Res Commun 434: 836-840, 2013.

KUBO S, DOE I, KUROKAWA Y, NISHIKAWA H, KAWABATA A: Direct inhibition of endothelial nitric oxide synthase by hydrogen sulfide: contribution to dual modulation of vascular tension. Toxicology 232: 138-146, 2007.

LI L, MOORE PK: Putative biological roles of hydrogen sulfide in health and disease: a breath of not so fresh air? Trends Pharmacol Sci 29: 84-90, 2008.

LOWICKA E, BELTOWSKI J: Hydrogen sulfide $\left(\mathrm{H}_{2} \mathrm{~S}\right)$ - the third gas of interest for pharmacologists. Pharmacol Rep 59: 4-24, 2007.

MALOU P, CIPOLLA MJ: Cerebrovascular dysfunction and blood-brain barrier permeability induced by oxidized LDL are prevented by apocynin and magnesium sulfate in female rats. J Cardiovasc Pharmacol 63: 33-39, 2013.

SAKAGUCHI M, MARUTANI E, SHIN HS, CHEN W, HANAOKA K, XIAN M, ICHINOSE F: Sodium thiosulfate attenuates acute lung injury in mice. Anesthesiology 121: 1248-1257, 2014.

SHIBUYA N, TANAKA M, YOSHIDA M, OGASAWARA Y, TOGAWA T, ISHII K, KIMURA H: 3-Mercaptopyruvate sulfurtransferase produces hydrogen sulfide and bound sulfane sulfur in the brain. Antioxid Redox Signal 11: 703-714, 2009.

STIPANUK MH: Sulfur amino acid metabolism: pathways for production and removal of homocysteine and cysteine. Annu Rev Nutr 24: 539-577, 2004.

STIPANUK MH, BECK PW: Characterization of the enzymic capacity for cysteine desulphhydration in liver and kidney of the rat. Biochem J 206: 267-277, 1982.

TANG G, WU L, LIANG W, WANG R: Direct stimulation of K(ATP) channels by exogenous and endogenous hydrogen sulfide in vascular smooth muscle cells. Mol Pharmacol 68: 1757-1764, 2005.

THOMPSON GA, DATKO AH, MUDD SH: Methionine synthesis in Lemna: inhibition of cystathionine gammasynthase by propargylglycine. Plant Physiol 70: 1347-1352, 1982.

VITVITSKY V, KABIL O, BANERJEE R: High turnover rates for hydrogen sulfide allow for rapid regulation of its tissue concentrations. Antioxid Redox Signal 17: 22-31, 2012.

WANG R: The gasotransmitter role of hydrogen sulfide. Antioxid Redox Signal 5: 493-501, 2003.

WEBB GD, LIM LH, OH VM, YEO SB, CHEONG YP, ALI MY, EL OAKLEY R, LEE CN, WONG PS, CALEB MG, SALTO-TELLEZ M, BHATIA M, CHAN ES, TAYLOR EA, MOORE PK: Contractile and vasorelaxant effects of hydrogen sulfide and its biosynthesis in the human internal mammary artery. J Pharmacol Exp Ther 324: 876-882, 2008.

XIAO L, WU YM, ZHANG H, LIU YX, HE RR: Hydrogen sulfide facilitates carotid sinus baroreflex in anesthetized rats. Acta Pharmacol Sin 27: 294-298, 2006.

XIAO L, WU YM, WANG R, LIU YX, WANG FW, HE RR: Hydrogen sulfide facilitates carotid sinus baroreceptor activity in anesthetized male rats. Chin Med J (Engl) 120: 1343-1347, 2007.

XU M, WU YM, LI Q, WANG X, HE RR: Electrophysiological effects of hydrogen sulfide on pacemaker cells in sinoatrial nodes of rabbits. Sheng Li Xue Bao 60: 175-180, 2008.

YAN H, DU J, TANG C: The possible role of hydrogen sulfide on the pathogenesis of spontaneous hypertension in rats. Biochem Biophys Res Commun 313: 22-27, 2004.

ZHANG D, LIU J, TU H, MUELLEMAN RL, CORNISH KG, LI YL: In vivo transfection of manganese superoxide dismutase gene or nuclear factor kappaB shRNA in nodose ganglia improves aortic baroreceptor function in heart failure rats. Hypertension 63: 88-95, 2014. 
ZHAO W, WANG R: H(2)S-induced vasorelaxation and underlying cellular and molecular mechanisms. Am J Physiol Heart Circ Physiol 283: H474-H480, 2002.

ZHAO W, ZHANG J, LU Y, WANG R: The vasorelaxant effect of H(2)S as a novel endogenous gaseous K(ATP) channel opener. EMBO J 20: 6008-6016, 2001.

ZHU YZ, WANG ZJ, HO P, LOKE YY, ZHU YC, HUANG SH, TAN CS, WHITEMAN M, LU J, MOORE PK: Hydrogen sulfide and its possible roles in myocardial ischemia in experimental rats. $J$ Appl Physiol 102: 261-268, 2007. 